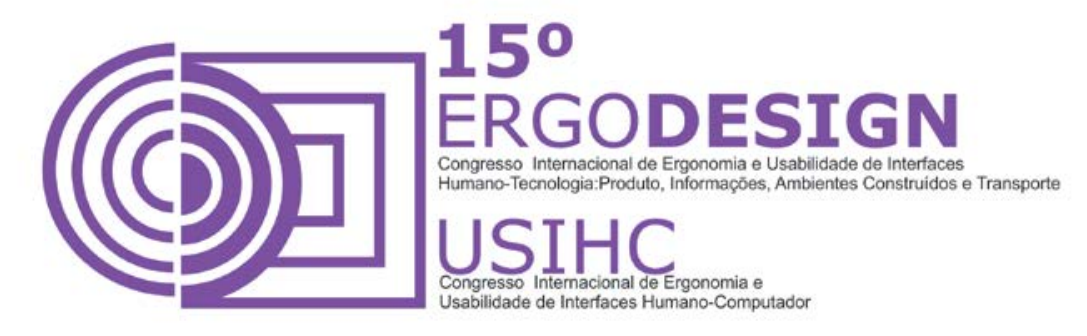

\title{
O MERCADO INFORMAL E A ERGONOMIA: UMA AVALIAÇÃO E PROJETO ERGÔNOMICO DE UMA RECHEADEIRA DE CHURROS
}

\section{THE INFORMAL MARKET AND ERGONOMICS: AN EVELUATION AND ERGONOMIC DESIGN OF A CHURROS RECHEADEIRA}

\author{
VASCONCELOS, Hortência Lira de (1); \\ VASCONCELOS, Angélica Lira de (2); \\ BARROS, Bruno (3) \\ (1) Universidade Federal de Pernambuco, Graduanda em Design \\ e-mail:hortencia lira@yahoo.com.br \\ (2) Universidade Federal de Pernambuco, Graduanda em Design \\ e-mail:angélica.Ivasconcelos@gmail.com \\ (3) Universidade Federal de Pernambuco, Mestre \\ e-mail:barros bruno@hotmail.com
}

\begin{abstract}
RESUMO
O mercado informal se configura como um grande setor que envolve diretamente seres humanos em postos de trabalho improvisados. Desta forma o referente artigo objetivou a análise e projeto conceitual para o redesign ergonômico do maquinário destinado a rechear churros. Instalado em uma carrocinha, o artefato possui diversos problemas relacionados ao uso e principalmente a ergonomia. Através de análises antropométricas, biomecânicas, analises de similares e amparados pela metodologia de intervenção ergonomizadora do sistema humano-tarefa-máquina, foi possível identificar e listar os problemas que o mesmo ocasionava ao usuário e estabelecer uma possível solução projetual para os mesmos.
\end{abstract}

Palavras-chave: Mercado, Ergonomia, Churros

\section{ABSTRACT}

The informal market is configured as a large sector that directly involves human beings in makeshift jobs. thus the related article aimed to analysis and conceptual design for ergonomic redesign of machinery designed to fill churros. housed in a wagon, the artifact has several problems related to the use and 


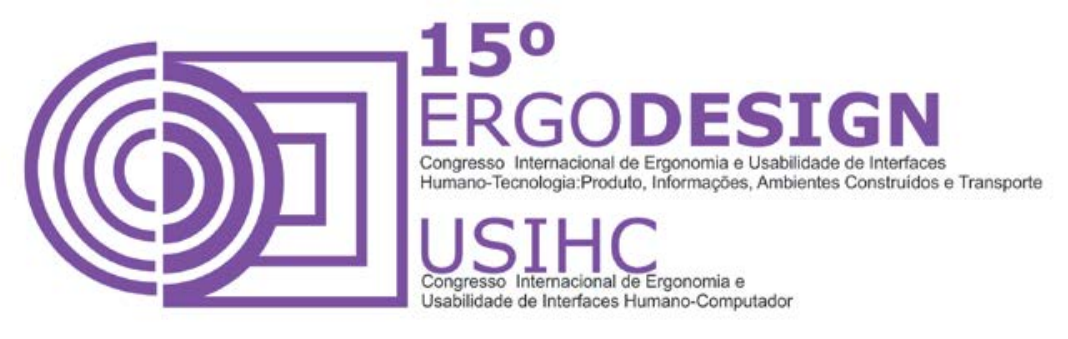

especially ergonomics. through anthropometric analysis, biomechanical, similar analyzes and supported by ergonomizadora intervention methodology of the human-machine-task system, it was possible to identify and list the problems that it occasioned to the user and establish a possible architectural design solution for the same.

Keywords: Market, Ergonomics, Churros

\section{INTRODUÇÃO}

Desde as civilizações antigas, o homem sempre buscou melhorar as ferramentas, os instrumentos e os utensílios que usa na sua vida cotidiana. Existem exemplos de empunhaduras de foices datadas de séculos atrás, que demostram a preocupação em adequar a forma da pega as características da mão humana, de modo que possa propiciar mais conforto na usabilidade durante sua utilização.

A ergonomia busca adequar a interface humano-máquina, de modo que as tarefas, postos de trabalho, produtos, ambientes e sistemas tornem-se compatíveis com as necessidades, habilidades e limitações das pessoas. Para tanto, faz uso de dados da Fisiologia, da neurofisiologia, psicofisiologia, da psicologia, da psicopatologia, da biomecânica ocupacional, bem como da anatomia e da antropometria.(MORAES \& SOARES, 2010).

Analisando e verificando na área de trabalho do profissional, foi identificado que tal artefato causava alguns danos/riscos ao corpo do indivíduo, com base nessas observações e verificações foi desenvolvido este projeto para melhoria de tal artefato, visando uma melhoria na pega do produto, na adequação à mão do usuário, para que assim possa minimizar os danos causados pelo esforço físico em contato com os membros superiores.

Com todas as informações sobre a área de trabalho levantadas, com base nos problemas encontrados no produto através das diretrizes preconizadas pelas etapas da metodologia de intervenção ergonomizadora do sistema-humano-tarefa-máquina, foi desenvolvida uma proposta de redesign da recheadeira de churros, incluindo materiais que se encaixam melhor na função e se aquedam melhor a mão do usuário, para assim sugerir e proporcionar melhora no artefato e consequentemente melhorar o trabalho do profissional.

Com a pesquisa, ficou claro que o objeto em estudo necessita de uma demanda de força e frequência por parte do usuário, pois pega-se o objeto faz-se movimentos de alavanca repetitivas vezes, trata-se um trabalho estático, onde ocorre fadiga de um determinado grupo de músculos após seu uso diário.

\section{FUNDAMENTAÇÃO TEÓRICA}

$\mathrm{Na}$ Ergonomia existe interatividade entre Humano-objeto e entorno. O que se vê com frequência, é que o homem passa a ter que se adaptar ao produto e não o contrário. Desse modo, o estudo ergonômico se impõe e é indispensável para alcançar a melhor solução 


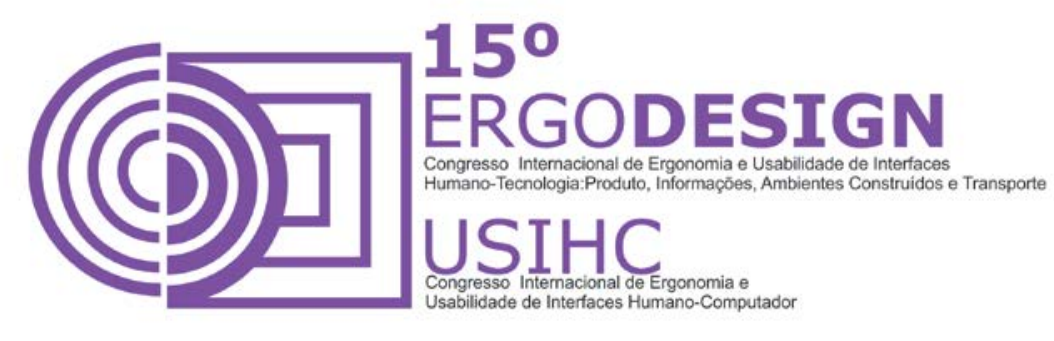

projetual para o objeto. Deve-se antes de se produzir um produto, desenvolver toda uma pesquisa e/ou a contratação de profissionais para projetar um produto que venha a ser funcional e ergonômico.

Finalmente, testificamos que a ergonomia tem como objetivo a partir de seus levantamentos, análises, pareceres, diagnósticos, recomendações, proposições e avaliações, o HUMANO como ser integral. Contribuindo em conhecimento atuante e reformando conceitos, impedindo a alienação de trabalhador. Um movimento cíclico, o ser humano é transformado, e transforma a sociedade.

Nos últimos anos, trabalhar como vendedor ambulante tornou-se uma fonte de renda para milhões de brasileiros. Uma opção para um novo pretendente ao trabalho ambulante é comercializar churros, um alimento bem apreciado por crianças e adultos.

O churros é um doce originário da Espanha, a guloseima é composta por uma massa à base de farinha, margarina, água e sal. Seu recheio original é o doce de leite, que passou a ser apenas uma das opções. Brigadeiro e leite condensado estão nas outras variações de recheio sendo o doce ainda salpicado com açúcar.

Para o preparo, o empreendedor faz uso de uma máquina de churros, que são acopladas a um carrinho. Há uma grande variedade de modelos, contudo, os melhores são os fabricados em aço inox e vidro, pois possibilitam melhor higienização. O posto de trabalho é sujeito a fiscalização da vigilância sanitária, portanto, precisa oferecer condições adequadas de higiene.

Para a realização do trabalho o funcionário utiliza-se de um carrinho equipado para assar e armazenar os churros. O posto de trabalho oferece nítidos riscos à saúde, o uso de material em altas temperaturas (óleo), em ambientes abertos e sem proteção, onde um simples acidente pode ocasionar queimaduras graves. O copo em inox permanece por um longo período de tempo quente, pois o recheio necessita de calor para ficar mais homogêneo.

O artefato em análise (recheadeira de churros) é utilizado para inserir o recheio nos churros comumente comercializados em feiras públicas e/ou eventos. Composto por copo em Aço Inox Escovado, base em alumínio polido e bico dosador de inox, tem capacidade de 5 litros de recheio.

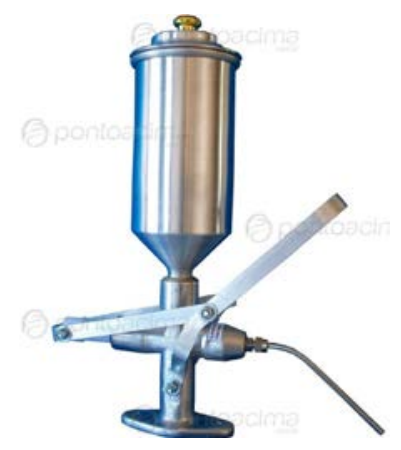

Figura 1: Recheadeira de churros. 


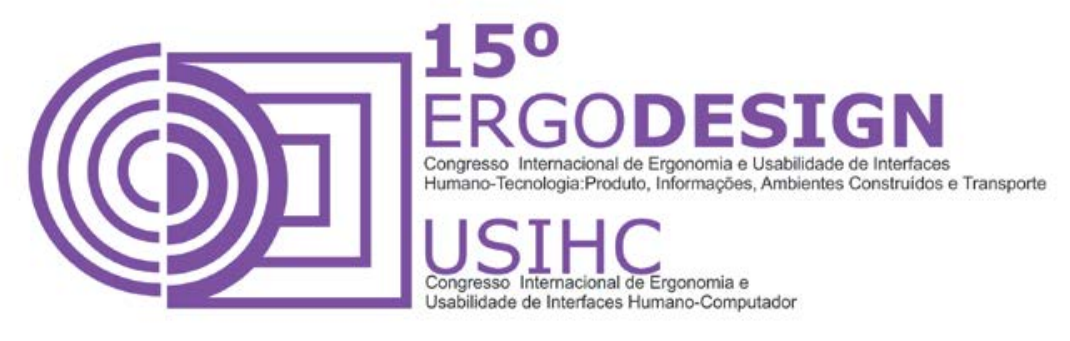

O produto fica fixo na maquina, é utilizado constantemente durante a jornada de trabalho de 6 a 8 horas diárias, aproximadamente sua alavanca é movimentada de 150 vezes (dias comuns de semana), 300 a 350 vezes (dias em eventos ).

\subsection{Considerações Antropométricas e Biomecânicas}

Os dados antropométricos podem ser utilizados no dimensionamento do espaço de trabalho e para dimensionar superfícies horizontais, nomeadamente, alcances sobre a mesa de trabalho, altura da mesa para trabalho sentado e altura da mesa para trabalho de pé.

Segundo Panero e Zelnik (2013), a antropometria é a ciência que trata especificamente das medidas do corpo humano para determinar diferenças em indivíduos e grupos. "Os dados antropométricos definem as medições de tamanho, peso e proporção do corpo humano aplicáveis a um correto dimensionamento de projeto de produtos, equipamentos e postos de trabalho" (SOARES \& MORAES, 2005). Baseado nessas informações, tende a projetar um ambiente de trabalho que se adeque as medidas e necessidades humanas, provendo assim maior conforto e segurança ao nosso usuário.

O dimensionamento da nova pega foi pensado conforme Grandjean (2005), quando afirma que as empunhaduras não adaptadas à anatomia da mão ou que pouco valorizam a biomecânica do trabalho, podem influenciar a produção e eventualmente causar danos à saúde do usuário.

Basicamente, o formato da pega respeitará os contornos da mão, contendo depressões para facilitar o contato dos dedos. As Dimensões da pega foram estabelecidas de acordo com Freivalds (1999), o qual determina, para que haja uma pega confortável, $22 \mathrm{~mm}$ de diâmetro (ou secção), 120mm de comprimento e ângulo (eixo da preensão em relação ao dedo indicador) de $60^{\circ}$ para manejo de precisão. Este dimensionamento serviu de referência para o projeto da pega. Cada sulco presente no revestimento da pega, terá $4 \mathrm{~mm}$ de profundidade no elastômero, afim de proporcionar um maior conforto e aderência na utilização.

O resultado dessas medições é de significativa importância para a adaptação de um produto ao usuário, proporcionando mais conforto, menos riscos de acidentes e de doenças causadas por má postura e movimentos incorretos.

Ao analisar o artefato utilizado para rechear churros, assim como o desempenho da atividade por parte do usuário, percebemos um nítido risco de incidência de DORTs. D.O.R.T. é o termo usado para designar Distúrbio Osteomuscular Relacionado ao Trabalho. A preocupação com tais distúrbios começou a ganhar notoriedade na década de $80 \mathrm{com}$ os primeiros casos de L.E.R. (Lesão por Esforço Repetitivo) que começaram a aparecer em digitadores.

Caracterizam todas doenças e alterações a nível de tendões, músculos, articulações, nervos e ossos. Causam muita dor e desconforto se não tratadas corretamente podem causar transtornos temporários ou permanentes.

Identificamos a possível incidência de três tipos de DORTs no posto analisado, decorrentes do uso prolongado do artefato em questão. A primeira delas são as Bolhas e calosidades, causadas pelo contato direto e repetitivo e com uso de força na pega em aço. O funcionário 


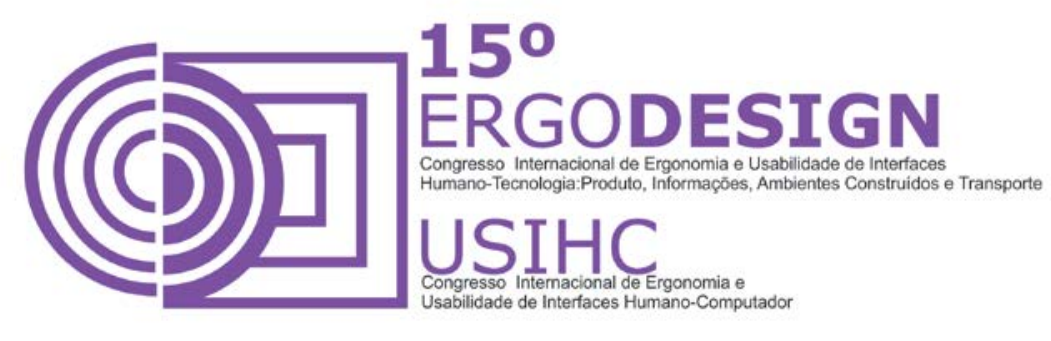

alegou a formação de liquido subcutâneo e camadas densas e secas na pele das mãos. Isso nos fez atentar para o estudo de um possível aumento da tração na pega do artefato, para evitar o atrito, além da distribuição da carga sobre uma superfície maior da pele.

Outro risco de DORT identificado foi o de problemas nas artérias, veias e nervos, ocasionados pela compressão de vasos capilares em decorrência da pega pequena e desproporcional aos dedos das mãos. O usuário reclamou de dores e desconfortos, vermelhidão e possíveis formigamentos. Isto nos fez atentar para um estudo do formato mais arredondado e inserção de um revestimento emborrachado na pega.

Por fim, encontramos o risco de incidência de problemas nos ossos e articulações, devido à força implicada na tarefa de pressionar a haste para a extrusão do churro pelo artefato. $O$ funcionário afirma sentir dores e desconfortos nas articulações do ombro, cotovelo e punho, bem como ao longo de todos os dedos das mãos. Isto nos fez atentar para repensar o sistema articular de compressão da massa de churro pelo artefato, bem como analisar o alcance, postura e movimento dos membros do usuário.

\section{PROCEDIMENTOS METODOLÓGICOS ADOTADOS}

Metodologia selecionada para o desenvolvimento do estudo foi a Metodologia de Intervenção Ergonomizadora do Sistema Humano - Tarefa - Máquina, desenvolvida por Moraes e Mont'Alvão (2010). Algumas etapas da metodologia foram elencadas e guiaram todo o estudo para o estabelecimento de recomendações ergonômicas de reformulação do posto de trabalho estudado.

\subsection{Apreciação Ergonômica}

A apreciação ergonômica é uma fase de mapeamento dos problemas ergonômicos da empresa. Nesta fase é feita a sistematização do sistema humano-tarefa-máquina e a delimitação dos problemas. Esta fase é de observações, entrevistas e registros dos operadores no seu local de trabalho, e termina com o parecer ergonômico, que é a apresentação ilustrada dos problemas e disfunções do sistema humano-tarefa-máquina.

O estudo de caso nos permitiu apontar diversos problemas do carrinho de churros. Dentre os problemas elencados podemos citar: a falta de assento confortável e na altura necessária para o acionamento da alavanca, evitando que a vendedora permaneça em pé todo o tempo, inexistência de proteção para pega, levando a usuária a utilizar tecido envolto da pega, a fim de não adquirir todo o calor oriundo do recheio. 

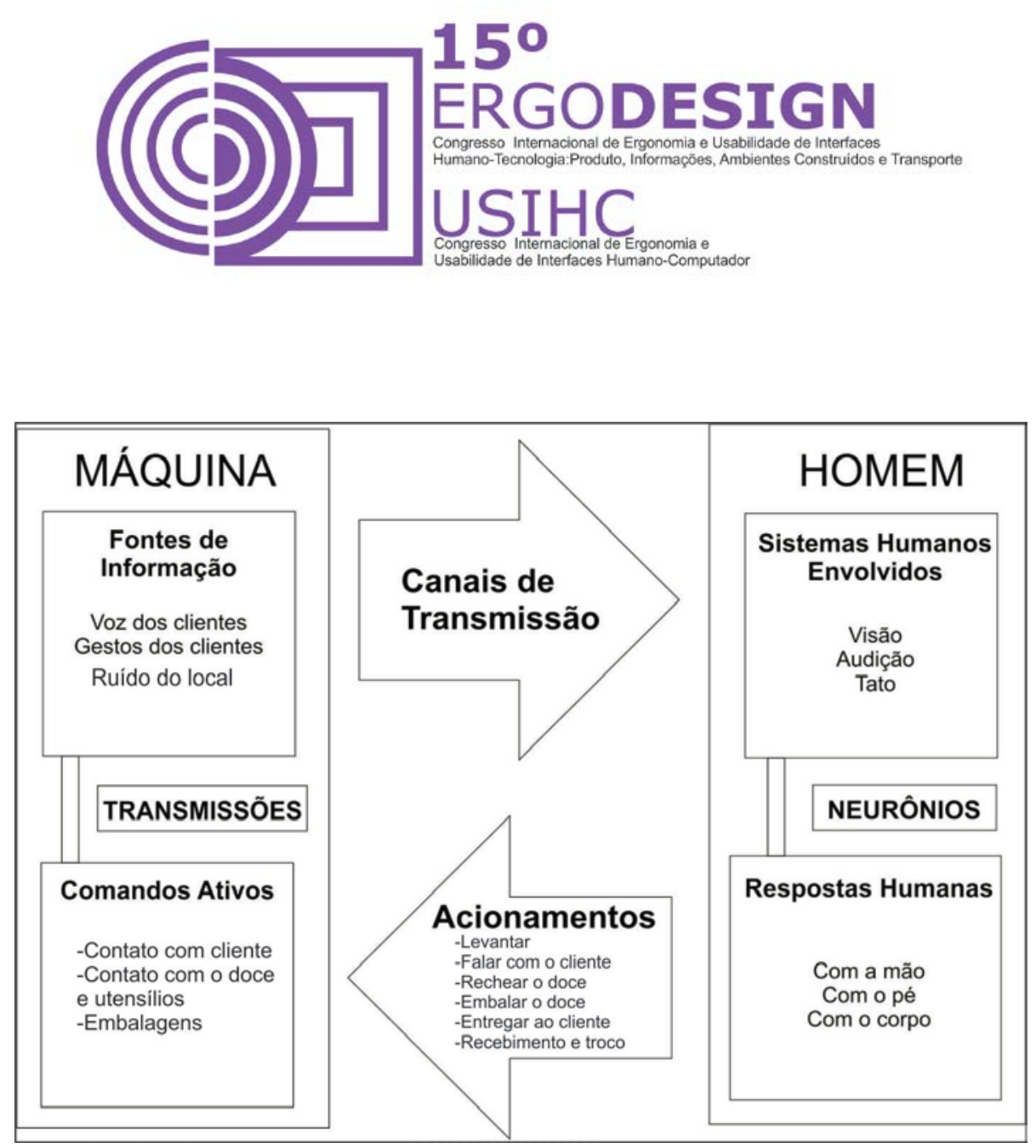

Figura 2: Modelagem comunicacional do sistema

Com base nas informações levantadas e problemas potenciais diagnosticados na apreciação ergonômica, verificamos a necessidade de uma intervenção ergonômica que melhore as condições e otimize as relações na interface operador/sistema do artefato aqui estudado. A partir de uma análise dos problemas encontrados, buscamos produzir um redesign que atenda da melhor maneira possível às necessidades do usuário em questão.

\subsection{Aplicação de Questionário}

O questionário da Escala de Corllet foi aplicado com o intuito de saber quais os desconfortos e dores decorrentes das atividades realizadas pela usuária do artefato. A escala de Corllet é um diagrama onde divide o corpo humano em segmentos diversos facilitando a localização em áreas no qual os trabalhadores sentem dores. Munido deste diagrama, entrevistamos a responsável pela execução no começo e final de um período de trabalho, pedindo para que ela apontasse regiões onde sente dores, em seguida pede-se para que avalie subjetivamente 0 grau de desconforto que sente em cada um dos segmentos indicados no diagrama. $O$ índice de desconforto é classificado em cincos níveis, que varia de um para "extremamente confortável" até o nível cinco, "extremamente desconfortável". 


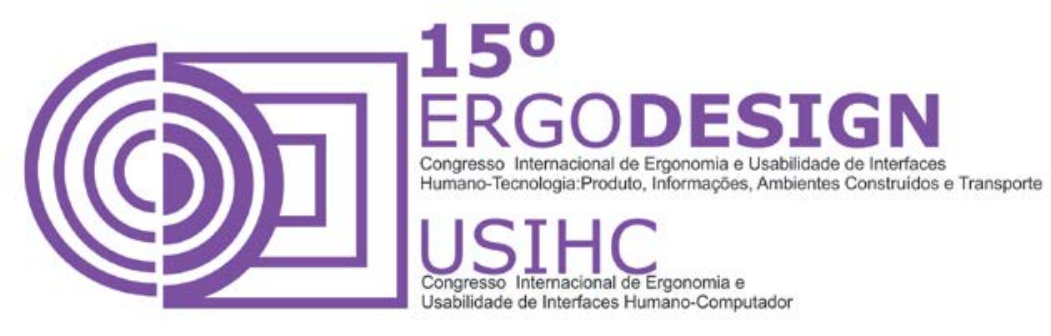

Sendo assim, o questionário foi respondido inicialmente às 7 horas da manhã, antes do início da jornada de trabalho, quando a vendedora ambulante geralmente chega ao local; $\mathrm{e}$ novamente às 17 horas da tarde próximo ao fim de expediente. Tendo assim respondido 0 questionário, avaliamos as dores causadas pelas atividades feitas no local de trabalho.

\subsection{Aplicação da Escala de Corllet}

O questionário da Escala de Corllet foi aplicado com o intuito de saber quais os desconfortos e dores decorrentes das atividades realizadas pela usuária do artefato. A escala de Corllet é um diagrama onde divide o corpo humano em segmentos diversos facilitando a localização em áreas no qual os trabalhadores sentem dores. Munido deste diagrama, o ergonomista entrevista os trabalhadores no começo e final de um período de trabalho, pedindo para que eles apontarem regiões onde sentem dores, em seguida pede-se para que avaliem subjetivamente 0 grau de desconforto que sentem em cada um dos segmentos indicados no diagrama.

O índice de desconforto é classificado em cincos níveis, que varia de 1 (um) para "extremamente confortável" até o nível 5 (cinco), "extremamente desconfortável". No teste de Corllet, a usuária não demonstrou incômodos ou dores no início do dia, as dores vão aumentando no decorrer do dia, através do uso repetitivo do produto.

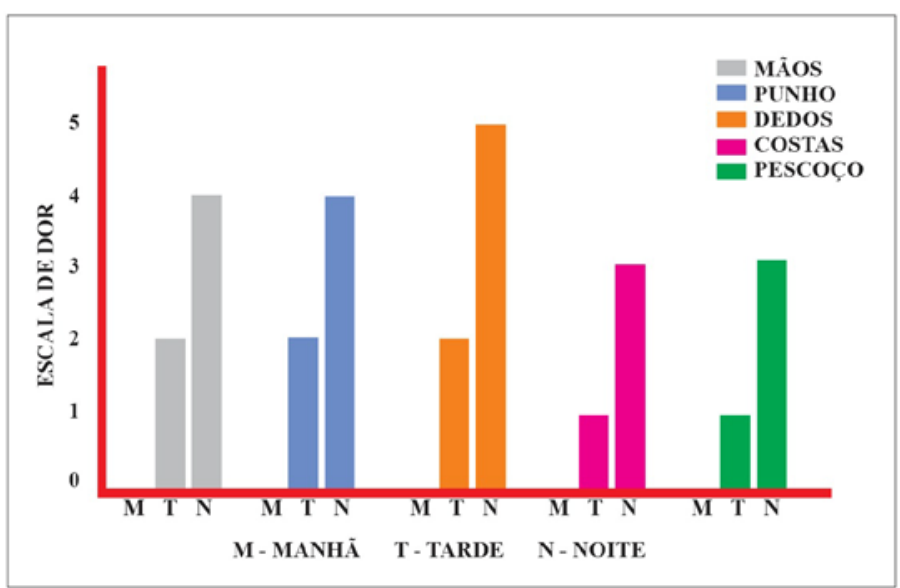

Gráfico 1: Resultados da escala de Corllet.

Através de entrevista realizada com responsável por operar a máquina diariamente, constatamos que seu uso traz desconforto, fortes dores musculares, cansaço físico, dor nos membros superiores e extremo desconforto nos dedos e palma da mão, resultado de um uso 


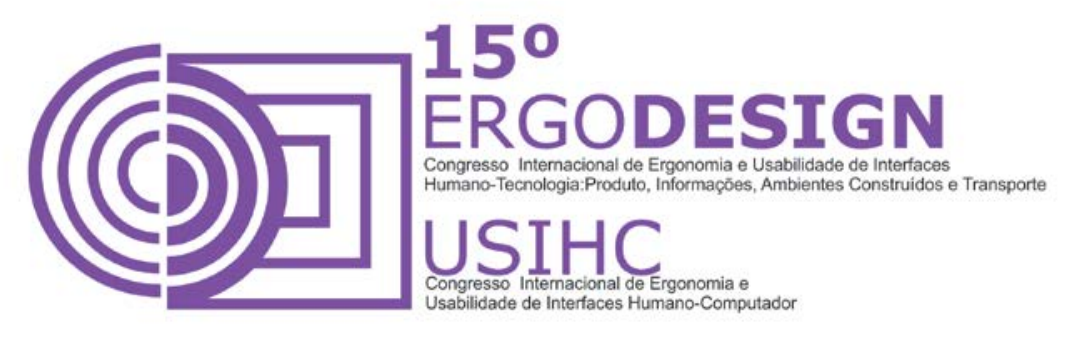

continuo (6 horas diárias), uma incorreta ergonomia da alavanca juntamente com uma posição corporal desconfortável e fatigante (em pé).

\subsection{Problematização Ergonômica}

Através da análise foi percebido que o funcionário ao longo do horário de trabalho está propício às possíveis lesões por esforço repetitivo e lesões que podem ser ocasionadas pela utilização do sistema de pega ineficiente do artefato, somado à impressão de força para realização da tarefa.

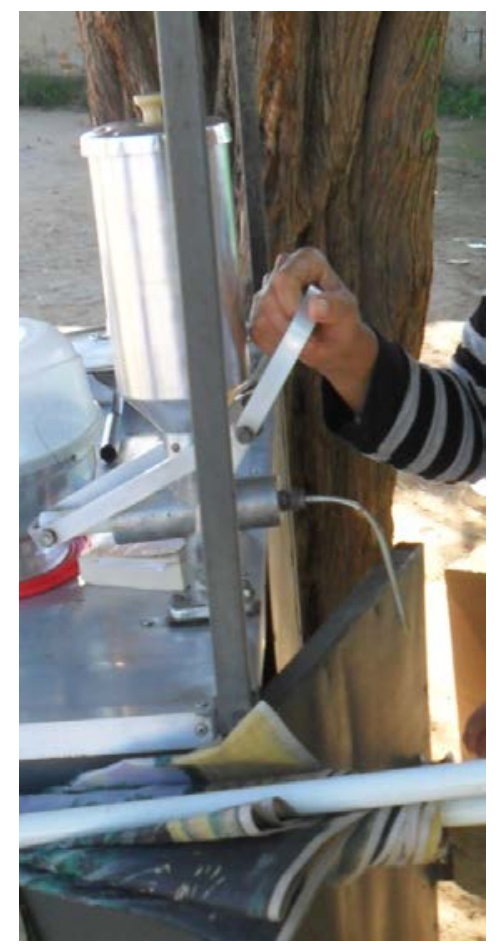

Figura 3 - Utilização da Recheadeira de Churros

O usuário tem dificuldades de utilizar a alavanca, pois sua pega tem tamanho e formato desproporcionais a mão, ao invés de posicionar a mão frontalmente ela utiliza a alavanca lateralmente. O material utilizado adquire calor juntamente com o restante do equipamento, dificultando o uso. $\mathrm{O}$ aço utilizado na alavanca não permite uma boa higienização e torna a pega escorregadia. 


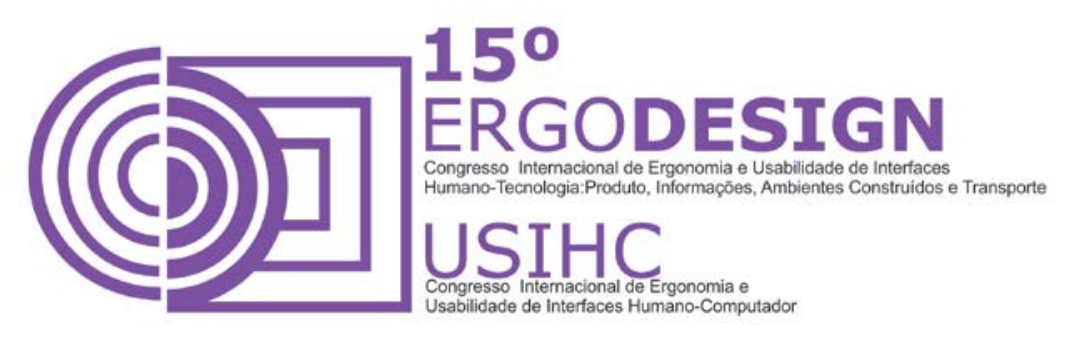

O usuário para exercer a tarefa de rechear os churros necessita utilizar movimentos de alavanca constantes com um dos membros superiores comumente usa-se o membro superior direito. Podendo acarretar lesões muscular nessa parte do corpo, por ser um esforço repetitivo.

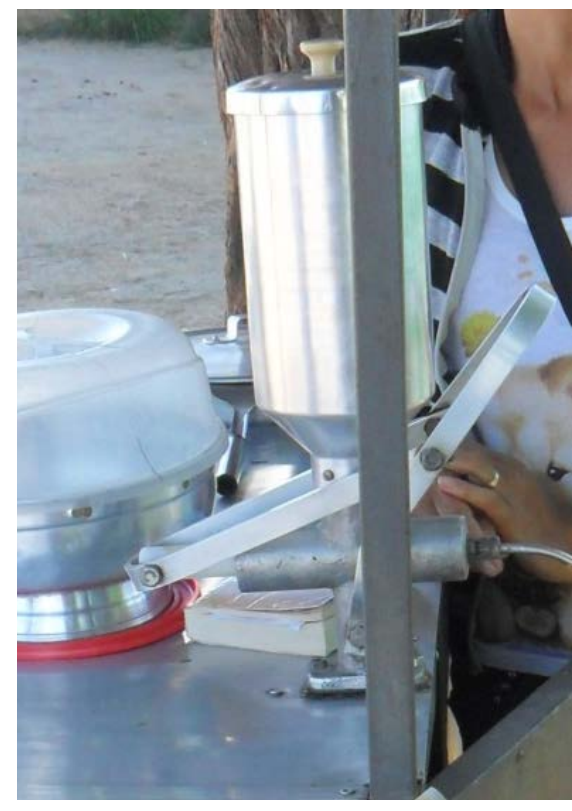

Figura 4 - Detalhe do sistema de alavanca da Recheadeira de Churros

\subsection{Análise de Similares}

Em adição às etapas selecionadas da metodologia do de intervenção ergonomizadora do sistema humano-tarefa-máquina, lançamos mão de análise de similares, com a necessidade de encontrar no mercado um ou mais similares que seriam utilizados para o redesign e verificar a possibilidade de existência/indicação de um modelo adequado à utilização humana. O resultado da pesquisa constatou uma gama de produtos com erros ergonômicos. 

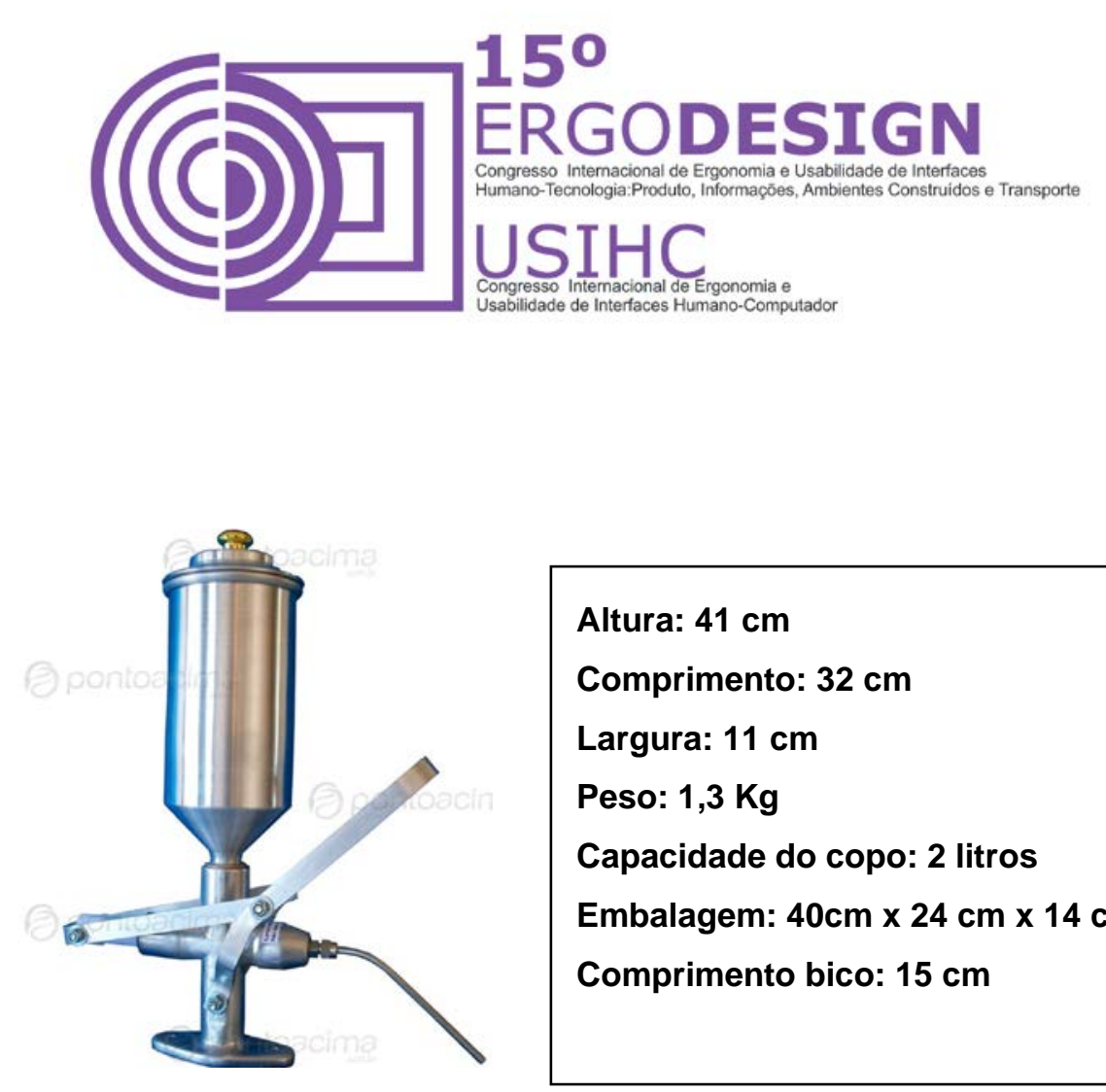

Altura: $41 \mathrm{~cm}$

Comprimento: $32 \mathrm{~cm}$

Largura: $11 \mathrm{~cm}$

Peso: $1,3 \mathrm{Kg}$

Capacidade do copo: 2 litros

Embalagem: $40 \mathrm{~cm} \times 24 \mathrm{~cm} \times 14 \mathrm{~cm}$

Comprimento bico: $15 \mathrm{~cm}$

Figura 5 - Modelo constante no posto de trabalho analisado.

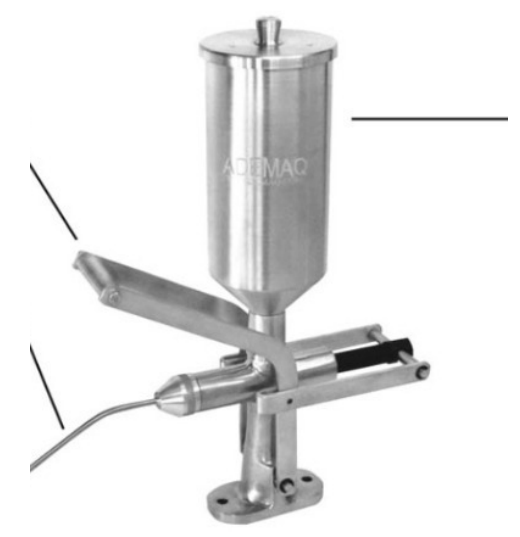

Figura 6 - Modelo 02

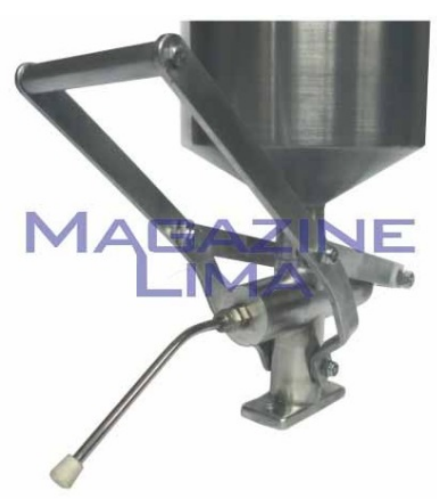

Figura 7 - Modelo 03

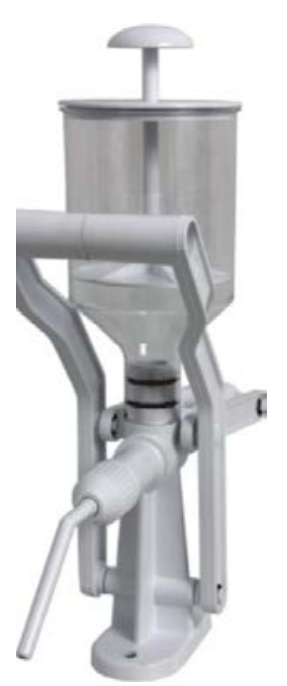

Figura 8 - Modelo em prolipropileno

O modelo dois (Figura 02) em analise possui uma pega circular mais extensa que a pega do nosso produto, também em aço dificulta o movimento pois a mesma movimenta-se de acordo com a força aplicada. Deixando a alavanca escorregadia. Foi colocada uma tampa no bico ejetor de recheio que prejudica o trabalho, é extremamente pequena o que dificulta sua retirada do bico. 


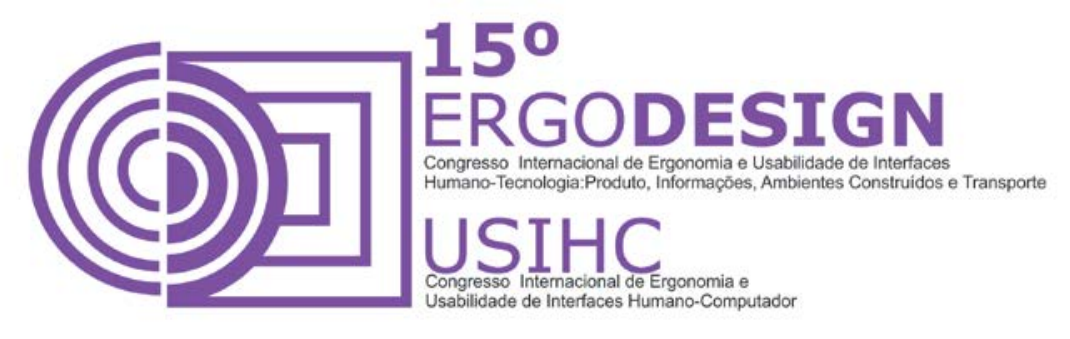

O modelo três (figura 03) em análise possui uma pega circular mais extensa que a pega do nosso produto, também em aço dificulta o movimento pois a mesma movimenta-se de acordo com a força aplicada. Deixando a alavanca escorregadia.

O modelo em polipropileno (figura 4) possui a pega maior que o produto do redesign mais com uma emenda na sua confecção (resultante do processo), causando incomodo na utilização. O material (polipropileno) é inadequado, pois não suporta e permite que a temperatura do recipiente permaneça estável, deixando a composição do recheio fria. Seu bico é curto levando em consideração o tamanho médio do alimento $(20 \mathrm{~cm})$ não sendo suficiente para rechear o alimento completamente. Após analisar todas as informações acima passou-se para fase de criação do novo produto após algumas tentativas finalmente no objeto final A alavanca sofreu maior modificação para adequação ergonômica.

Os materiais originais foram mantidos, acrescentando-se uma proteção na nova alavanca de elastômero.

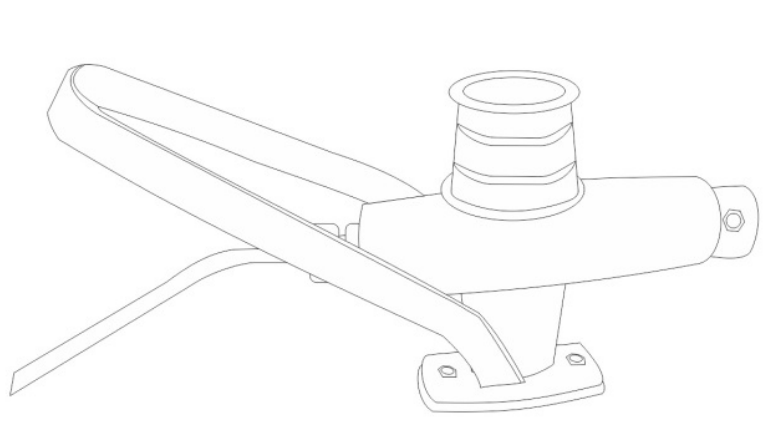

Figura 8 - Modelo Original

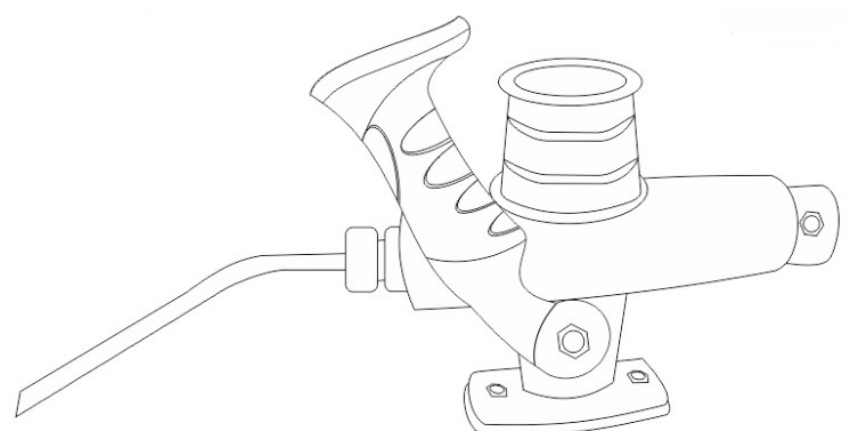

Figura 9 - Modelo Redesign

\section{CONCLUSÕES E CONSIDERAÇÕES FINAIS}

Após análise de pontos na antropometria, na biomecânica, com foco na ergonomia, pôde-se chegar a um artefato que possibilita uma melhor movimentação para que a usuária possa desenvolver seu trabalho com conforto e segurança, da alavanca.

A principal mudança sugerida é a modificação do material base da alavanca de alumínio, para elastômero, evitando qualquer D.O.R.T ((lesão por esforço repetitivo), principal motivo para 0 início dessa pesquisa. Ressaltando que apesar do redesign na alavanca seu uso deve seguir a 


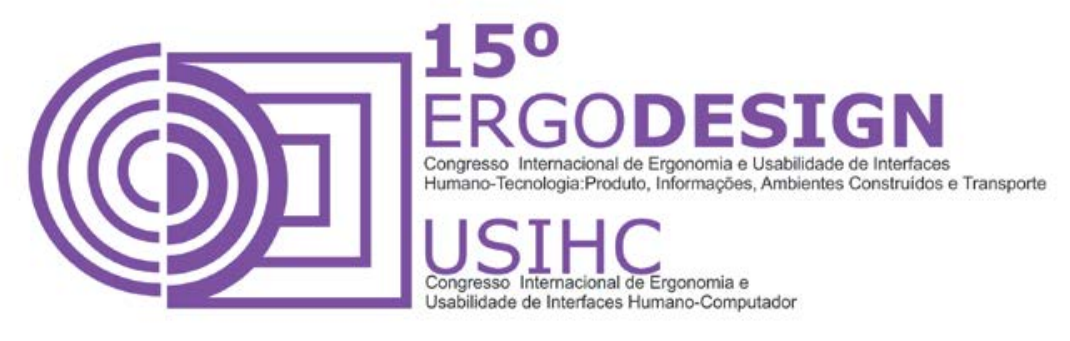

carga horaria de 6 horas diárias, afim de garantir uma melhor eficiência das melhorias realizadas. Outro fator relevante em sua modificação é o fato de que o produto do redesign deve ser reposicionado para uma localização na altura do cotovelo do usuário, assim como no alcance frontal da mão do mesmo, do contrário de nada adiantará o projeto ergonômico do artefato.

Neste sentido, reuniram-se informações teóricas da revisão bibliográfica e práticas da pesquisa de campo, obtendo um documento que servirá de Guia para se determinar aspectos ergonômicos das pegas para recheadeiras de churros, as quais irão influenciar diretamente na usabilidade, segurança e bem estar dos usuários. Além das conclusões técnicas referentes aos objetivos delimitados para a pesquisa em questão, vale salientar as conclusões a partir da experiência adquirida durante o desenvolvimento deste trabalho, as quais poderão servir de base para outros pesquisadores e profissionais.

\section{REFERÊNCIAS}

ASSOCIAÇÃO BRASILEIRA DE NORMAS TÉCNICAS - NBR 10152: níveis de ruído para conforto acústico. Rio de Janeiro, $1987.4 \mathrm{p}$.

DUL. Jan. Ergonomia prática 1954. Editora Blucher $2^{\circ}$ edição, tradutor Itiro lida 2004.

FILHO. João Gomes. Ergonomia do objeto: sistema técnico de leitura ergonômica.

GRANDJEAN, E. Manual de Ergonomia: Adaptando o trabalho ao homem. 5.ed. Porto Alegre: Artes Médicas, 2005.

IIDA, Itiro. Egonomia: projeto e produção. $2^{\mathrm{a}}$ edição. São Paulo: Edgard Blucher, 2005.

Ler/DORT. Cuidados para a sua saúde. Disponível em <http://www.lerdort.com.br>Acesso em 16/01/2015.

MORAES, Anamaria; MONT'ALVÃO, Cláudia. Ergonomia: Conceitos e aplicações. Rio de Janeiro: 2AB, 2010.

NORMA ISO 11064-6:2005 Disponível em:

http://www.iso.org/iso/catalogue detail.htm?csnumber=39713. Acessado em 16/01/201.

PANERO, J., ZELNIK, M. Dimensionamento Humano para Espaços Interiores. Gustavo Gili, Barcelona, 2013.

SOARES, M. M. \& MORAES, A. de. Ergonomia Princípios e Métodos. Apostila Curso de Especialização - Departamento de Design, Universidade Federal de Pernambuco, 2003.

VILLAROUCO, V. O ambiente está adequado? Anais do ENEAC 2007: I Encontro Nacional de Ergonomia do Ambiente Construído e II Seminário Brasileiro de Acessibilidade Integral. Recife, 2007. 